\title{
DESENVOLVIMENTO DE AÇO ALTO CARBONO BAIXA LIGA NA ARCELORMITTAL TUBARÃO E NA WAELZHOLZ BRASMETAL LAMINAÇÃO PARA APLICAÇÃO FINAL EM CORRENTE DE MOTOSSERRA*
}

\author{
André Sereno Lopes ${ }^{1}$ \\ Fábio Stagetti \\ Fernando Generoso Neiva Ferreira ${ }^{3}$ \\ Gabriel Godinho Alves ${ }^{3}$ \\ Maurício Franco Bomfim 4 \\ Ralph Telles dos Anjos ${ }^{5}$ \\ Thomas Frank ${ }^{6}$
}

\section{Resumo}

Os aços alto carbono baixa liga são amplamente utilizados, principalmente em componentes que necessitam de elevada resistência mecânica, manutenção de forma e resistência à abrasão. São largamente aplicados em lâminas de corte, molas, peças de segurança, implementos agrícolas, utensílios, serras em geral, entre outros. Neste trabalho, estudam-se, em escala industrial, os parâmetros de processo, as características críticas para o desenvolvimento e as propriedades mecânicas e metalúrgicas de um aço alto carbono baixa liga especialmente desenhado para a produção de correntes de motosserra. Utilizando ensaios de tração, dureza, microscopia óptica (MO) e eletrônica de varredura (MEV), avalia-se a evolução das características mecânicas e metalúrgicas do aço estudado.

Palavras-chave: Aço alto carbono; corrente de motosserra; ArcelorMittal Tubarão; Waelzholz Brasmetal Laminação.

\section{DEVELOPMENT OF HIGH CARBON LOW ALLOY STEEL IN ARCELORMITTAL TUBARÃO AND WAELZHOLZ BRASMETAL LAMINAÇÃO FOR THE FINAL APPLICATION ON CHAINSAW CHAIN}

\section{Abstract}

High carbon low alloy steels are widely used, mainly on parts that require high mechanical properties, form maintenance and abrasion resistance. They are largely applied on cutting blades, springs, safety parts, agricultural implements, utensils, saw in general, etc. In this paper was studied, in an industrial scale, the process parameters, critical characteristics for the development and the mechanical and metallurgical properties of a high carbon low alloy steel specially developed for the production of chainsaw chain. Using tensile test, hardness test, optical microscopy $(\mathrm{OM})$ and scanning electron microscopy (SEM) were evaluated the evolution of the mechanical and metallurgical characteristics of the studied steel.

Keywords: High carbon steel; chainsaw chain; ArcelorMittal Tubarão; Waelzholz Brasmetal Laminação.

\footnotetext{
M.Sc., Gerente de Desenvolvimento de Produto da Waelzholz Brasmetal Laminação, SP, Brasil. M.Sc., Coordenador de Controle de Qualidade da Waelzholz Brasmetal Laminação, SP, Brasil. M.Sc., Especialista de Desenvolvimento de Produtos da ArcelorMittal Tubarão, Vitória, ES, Brasil. Engenheiro Metalurgista, Gerente de Compras, Qualidade e Planejamento da WBL, SP, Brasil. Bel em Ciências Contábeis, Esp. Assistência Técnica da ArcelorMittal Tubarão, Vitória, ES, Brasil. Eng. de Materiais., Eng. Assist. Téc. e Desenvolv. da Waelzholz Brasmetal Laminação, SP, Brasil.
} 


\section{INTRODUÇÃO}

Motosserras são ferramentas de corte mecânicas, normalmente movidas por motores à combustão, configuradas com elementos cortantes anexos a uma corrente, chamada corrente de motosserra. Estes equipamentos são comumente utilizados no corte de madeira, em diversas situações, concreto ou mesmo gelo. Devido a esta multifuncionalidade da corrente de motosserra e do conceito mecânico do corte, as condições de preparo e aplicação exigem alta resistência ao desgaste, resistência ao impacto e resistência à fadiga. Estes requisitos são associados à tenacidade, limpidez do aço (baixos níveis de inclusões não metálicas) e resistência mecânica.

\subsection{Aços alto carbono baixa liga}

Os aços alto carbono baixa liga são amplamente utilizados, principalmente em componentes que necessitam de elevada resistência mecânica, manutenção de forma e resistência à abrasão. São largamente aplicados em lâminas de corte, molas, peças de segurança, implementos agrícolas, utensílios, serras em geral, entre outros (Figura 1).
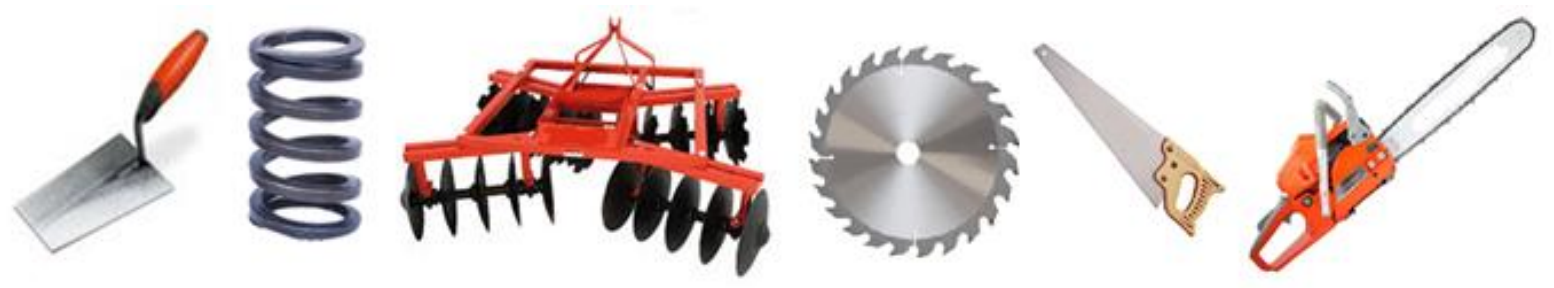

Figura 1. Algumas aplicações de aços alto carbono baixa liga: Utensílios, molas, implementos agrícolas, serras circulares, serrotes e correntes de motosserras.

Devido ao seu elevado teor de carbono e teores consideráveis de elementos de liga, estes aços possuem alta temperabilidade, ou seja, a austenita apresenta grande capacidade de transformar-se em martensita ou bainita, mesmo quando a velocidade de resfriamento é relativamente baixa. Inversamente, em aços de baixa temperabilidade, a martensita ou bainita somente poderão ser produzidas se as transformações difusionais da austenita forem impedidas pela utilização de elevadas taxas de resfriamento.

\subsubsection{Mecanismos de formação microestrutural}

Para velocidades de resfriamento baixas, a transformação eutetóide $\left(\gamma \rightarrow \alpha+\mathrm{Fe}_{3} \mathrm{C}\right)$ ocorre após pequeno super-resfriamento e em condição próxima do equilíbrio, resultando em uma microestrutura grosseira, constituída de uma matriz ferrítica com partículas de carboneto, denominada esferoidita (Figura 2a). Já para uma velocidade ligeiramente superior, perlita grosseira é formada (Figura 2b). As transformações que se iniciam a temperaturas menores (maiores graus de super-resfriamento), e, portanto, estão susceptíveis a maiores taxas de nucleação e menor difusão de carbono, apresentando então microestrutura mais refinada (Figura 2c). Quando a austenita é resfriada a velocidades suficientemente elevadas, esta é super-resfriada tão bruscamente que a transformação em ferrita $(\alpha)$ e cementita $\left(\mathrm{Fe}_{3} \mathrm{C}\right)$ é suprimida, 
e uma nova fase, não prevista no diagrama $\mathrm{Fe}-\mathrm{C}$, denominada martensita pode ser formada (Figura $2 \mathrm{~d}){ }^{1}$

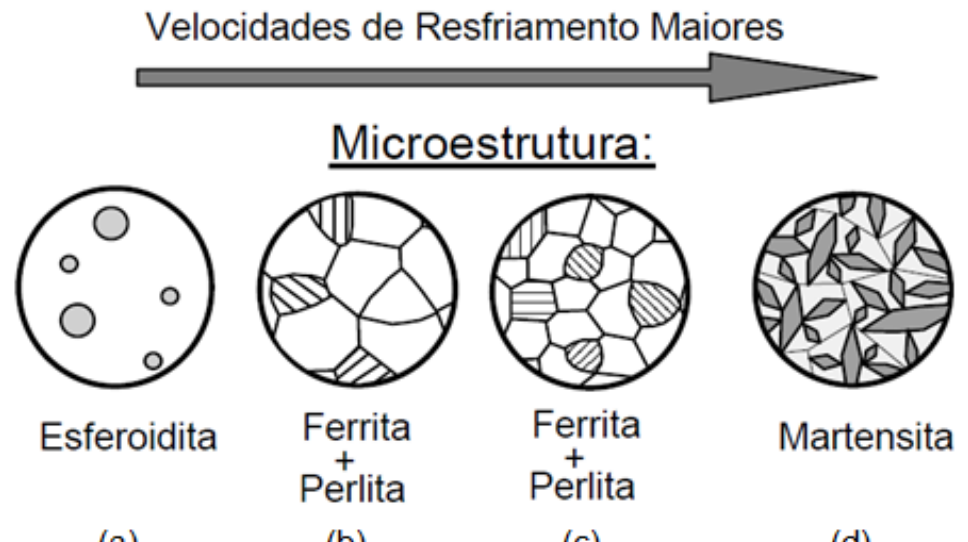

(a)

(b)

(c)

(d)

Figura 2. Microestrutura de um aço hipoeutetóide em função de sua velocidade de resfriamento a partir do campo austenítico. ${ }^{1}$

\subsubsection{Perlita}

Bhadeshia (1998) descreve a perlita como uma colônia formada por um bi-cristal de cementita e ferrita intercalados na forma de lamelas. Devido a sua estrutura de natureza lamelar, a redução da espessura das lamelas de perlita não resulta em um aumento significativo da tenacidade, pois uma trinca continuaria tendo um caminho preferencial para propagação, embora esta redução implica diretamente no aumento da resistência mecânica a tração. ${ }^{2,3}$

\subsubsection{Bainita}

Apesar da Figura 2 não mostrar, entre a morfologia da perlita, cada vez mais refinada, e a martensita, para alguns aços e condições de resfriamento, faz-se presente a formação do constituinte bainita (Figura 3), ou melhor, mistura de fases ferrita e carbonetos com disposição e dimensão distinta destes quando comparado a condição da perlita. A bainita é formada normalmente a temperaturas abaixo da formação da perlita e acima da martensítica. A energia de ativação da nucleação bainítica depende diretamente da força de transformação. ${ }^{4}$

A velocidade de transformação bainítica é considerada um fator que caracteriza as etapas de sua formação. Primeiramente uma subunidade de natureza ferrítica é nucleada no contorno do grão austenítico, esta cresce longitudinalmente com uma certa velocidade (estágio 1 na Figura 3), até que seu desenvolvimento é retido pela deformação plástica da austenita, e alguma formação de carbonetos ocorre ao seu redor e/ou no seu interior (estágio 2 na Figura 3). Então, novas subunidades são nucleadas a partir da primeira subunidade nucleada, desenvolvendo-se assim uma estrutura de feixe conforme o processo continua (estágio 3 na Figura 3). Neste caso, os carbonetos encontram-se entre as ripas de ferrita, o que caracteriza a formação da chamada bainita superior (Figura 3 - esquerda). Enquanto na bainita inferior (Figura 3 - direita), que além da precipitação de carbonetos entre as ripas de ferrita ocorrem também no seu interior. ${ }^{4,5}$ As faixas de temperatura apresentadas na 
Figura 3 são apenas indicativas, pois a mesma é influenciada pela composição química local do material em transformação.

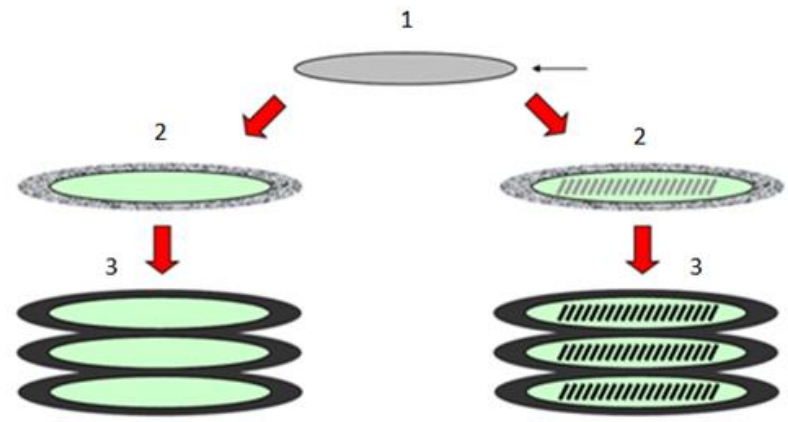

Bainita Superior $\left(500-450^{\circ} \mathrm{C}\right) \quad$ Bainita Inferior $\left(400-250^{\circ} \mathrm{C}\right)$

Figura 3. Diferença microestrutural entre bainita superior e inferior. ${ }^{4}$

\subsubsection{Martensita}

A transformação martensítica, também conhecida como "transformação militar", é, em sua essência, uma transformação adifusional, ou seja, sem difusão a longas distâncias. Desta forma, ela acontece através da movimentação coordenada de muitos átomos simultaneamente em distâncias pequenas (menores que os parâmetros da rede). Em geral, a fase mãe e a martensita apresentam correlações cristalográficas entre si. Esta transformação acontece com alteração de forma e volume, que aumenta significantemente a densidade de defeitos cristalinos (e.g.: discordâncias), produzindo microestruturas de elevada resistência mecânica. ${ }^{6}$

\subsubsection{Efeito dos elementos de liga}

A elevação dos teores de elementos de liga nos aços tende a aumentar o tempo necessário para a transformação da austenita, o que implica no incremento da temperabilidade, ou seja, a transformação martensítica se torna mais factível. A granulação e homogeneidade da austenita também afetam sua transformação, desta forma, estruturas austeníticas mais grosseiras e homogêneas, resultantes de austenitização em temperaturas excessivamente elevadas e/ou por períodos muito longos, tendem a sofrer transformações mais lentas. ${ }^{7}$

Os elementos de liga têm influência considerável na cinética e mecanismos dos três tipos de transformação da austenita e seus produtos: transformações difusional (ferrita e perlita), mista (bainita) e adifusional (martensita). Elementos de liga que se dissolvem somente em ferrita e cementita sem a formação de carbonetos especiais exercem apenas efeito quantitativo no processo de transformação de fase (Figura 4a). O cobalto acelera as transformações, enquanto a maioria dos elementos, incluindo $\mathrm{Ni}, \mathrm{Si}, \mathrm{Cu}, \mathrm{Al}$, etc., retardam. ${ }^{8}$

Elementos formadores de carbonetos, além de aumentarem a resistência ao desgaste, produzem mudanças tanto quantitativas quanto qualitativas na cinética das transformações isotérmicas (Figura 4b). Estes elementos (Cr, Mo, W, V, etc.) influenciam na decomposição da austenita a diferentes temperaturas:

I. $\quad 700-500^{\circ} \mathrm{C}$ (Transformação ferrítica e/ou perlítica): retardam a transformação; 
II. $500-400^{\circ} \mathrm{C}$ : retardam drasticamente a transformação;

III. $\quad 400-300^{\circ} \mathrm{C}$ (Transformação bainítica): aceleram a transformação.

Portanto, aços ligados com elementos formadores de carbonetos (teores elevados, acima de $10 \%$ ) possuem dois máximos de decomposição isotérmica da austenita separados por uma região de relativa estabilidade austenita sub-resfriada. ${ }^{8}$
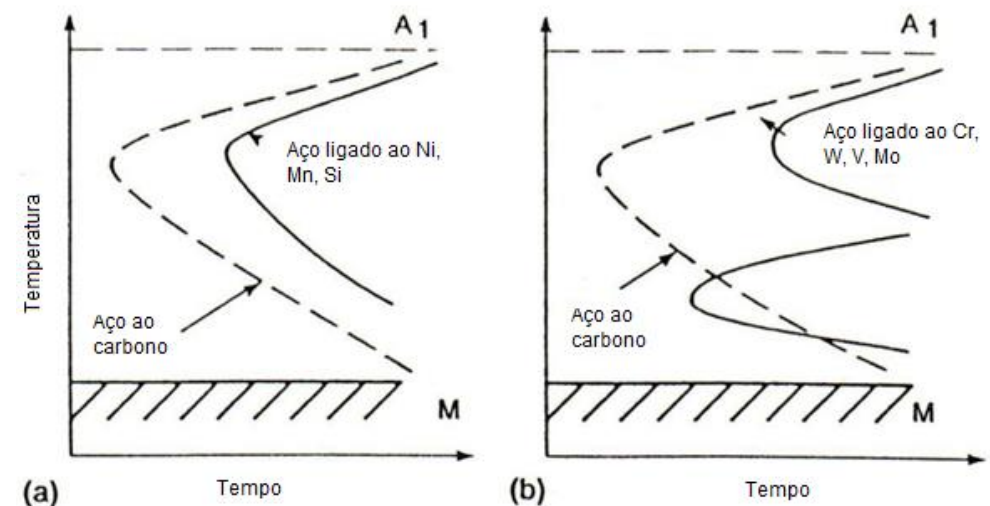

Figura 4. Diagramas esquemáticos de transformações isotérmicas (ITT). (a) Aço ao carbono e aço ligado com elementos não formadores de carbonetos; (b) Aço ao carbono e aço ligado com elementos formadores de carbonetos. ${ }^{8}$

\subsection{Corrosão intergranular}

O aço, durante seu processo de produção, sofre uma série de processos a altas temperaturas em atmosferas ricas em oxigênio e, como resultado, uma camada de óxido de ferro, também conhecida como carepa, se forma na superfície da tira. Nas etapas de resfriamento e bobinamento da tira de aço laminada a quente, as espiras internas não ficam expostas a uma atmosfera rica em oxigênio, entretanto o equilíbrio ferro-wüstita libera uma pequena quantidade de oxigênio, que é suficiente para induzir a oxidação interna. Esta pode transcorrer de duas maneiras: dentro dos grãos (corrosão uniforme) ou ao longo dos contornos de grão (corrosão intergranular). ${ }^{9}$

A oxidação seletiva altera as propriedades mecânicas do aço, principalmente devido a sua contribuição na corrosão intergranular. Os contornos de grão são considerados atalhos para a difusão e este tipo de oxidação está diretamente ligada a estrutura atômica destes contornos. Os óxidos presentes ao longo dos contornos de grão levam ao enfraquecimento da força coerciva entre os grãos, causando fragilização severa após processos de deformação. Desta forma, a corrosão intergranular é influenciada principalmente pela temperatura de bobinamento, estrutura atômica dos contornos de grão e reações de difusionais ao longo dos contornos de grão. ${ }^{10}$

\section{MATERIAIS E MÉTODOS}

\subsection{Material}

$\mathrm{O}$ aço tratado neste trabalho, BW BL 8660 , foi especialmente desenvolvido para aplicação em corrente de motosserra, apresentando boa conformabilidade (como fornecido), temperabilidade e, após austêmpera, elevadas dureza e resistência ao 
desgaste. Devido ao seu elevado teor de liga ( $\mathrm{C}, \mathrm{Cr}, \mathrm{Ni}$ e $\mathrm{Mo}$ ), a produção de aços alto carbono é extremamente crítica para todos os processos siderúrgicos, que devido a questões de sigilo industrial os valores são apresentados em faixas, Tabela 1.

Tabela 1. Composição química do aço estudado

\begin{tabular}{cccccc}
\hline $\mathbf{C ~ ( \% )}$ & Mn (\%) & Si (\%) & Ni (\%) & Cr (\%) & Mo (\%) \\
\hline $0,60-0,75$ & $0,30-0,70$ & $0,20-0,50$ & $0,20-0,50$ & $0,20-0,50$ & $0,05-0,30$ \\
\hline
\end{tabular}

O material utilizado neste trabalho foi produzido como bobina laminada a quente (BQ) pela ArcelorMittal Tubarão (Aciaria / Lingotamento contínuo / Resfriamento lento / Reaquecimento de placas / Laminação a quente / Embalagem), Figura 5, e processado pela Waelzholz Brasmetal Laminação (Decapagem / Corte longitudinal / Laminação de Desbaste / Recozimento / Laminação de Acabamento / Recorte / Embalagem), Figura 6, para o fornecimento na forma de rolo ao cliente final.

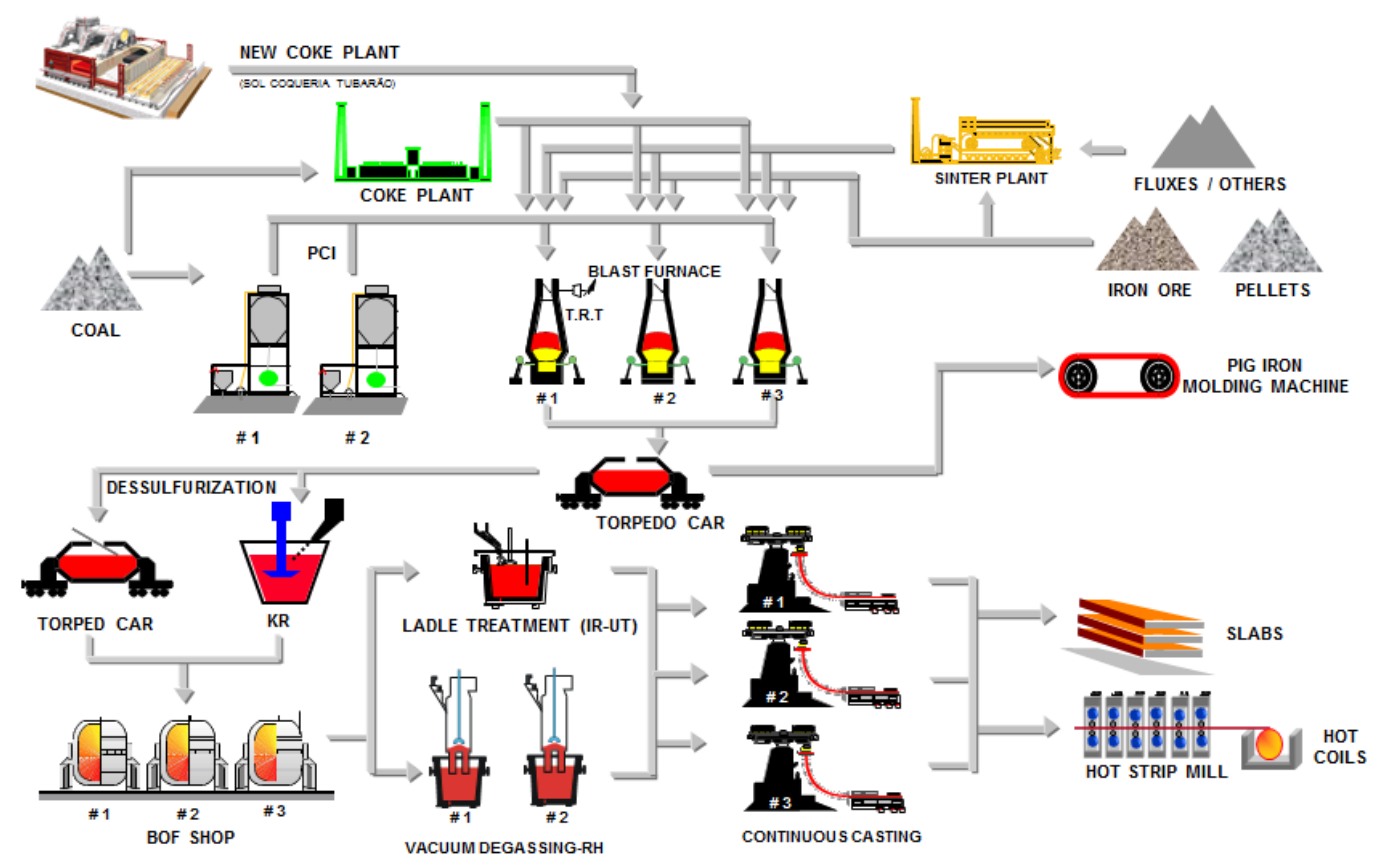

Figura 5. Fluxograma de produção da ArcelorMittal Tubarão.

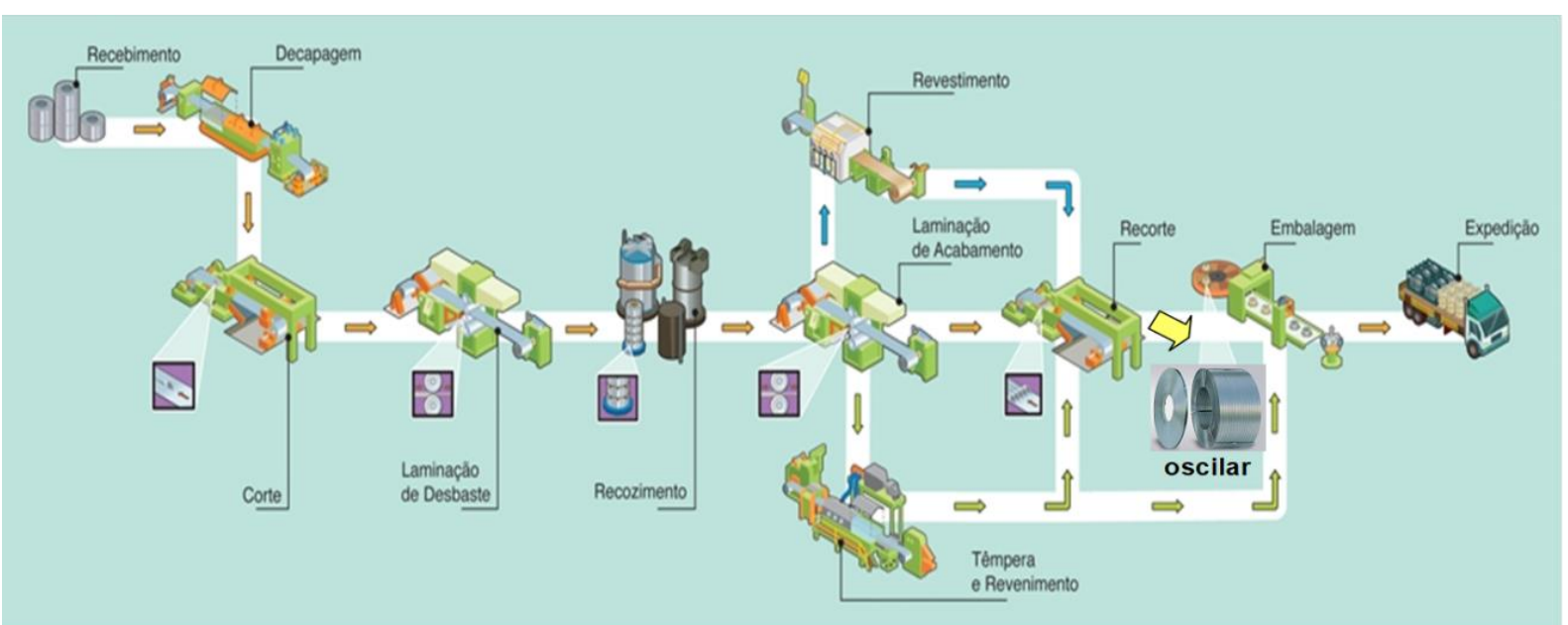

Figura 6. Fluxograma de produção do aço BW BL 8660 na Waelzholz Brasmetal Laminação (linha principal sem processos auxiliares) 
Para a produção deste aço, que apresenta elevados teores de $\mathrm{C}, \mathrm{Cr}$, Ni e Mo, uma série de controles se fazem necessários, como, por exemplo:

- Conversor LD: gestão de matérias primas de adição (ferro ligas e grafite) ordem das adições, controle dos teores de $\mathrm{S}$ e $\mathrm{P}$ e temperatura de final de sopro;

- Desgaseificador a vácuo RH: circulação eficaz de aço (homogeneização) e controle do teor de S e de super heat;

- Lingotamento Contínuo: controle prévio de espaçamento e alinhamento dos segmentos, calibração do fator de contração, controle de velocidade de lingotamento, controle de profundidade e selagem de válvulas (longa e submersa) e não realizar mudança de largura;

- Condicionamento de placas: resfriamento lento em fossa ou campânula e cuidado no manuseio;

- Laminação a quente: controle das temperaturas de acabamento e bobinamento e velocidade final de laminação (controle da taxa de resfriamento);

- Decapagem: controle da temperatura dos banhos e da velocidade de decapagem;

- Laminação a frio: controle da espessura, velocidade de laminação, carga de laminação e tração nas bobinadeiras;

- Recozimento: controle do gradiente de temperatura, tempo de encharque e taxa de resfriamento;

- Acabamento: controle da espessura, velocidade de laminação, carga de laminação, tração nas bobinadeiras, rugosidade superficial e forma da tira.

\subsection{Métodos}

\subsubsection{Ensaio de Macro ataque}

As amostras de placa (transversal e longitudinal) foram preparadas da seguinte forma: corte a gás, fresa para nivelamento da superfície e lixamento utilizando lixadeira pendular. As amostras são atacadas com solução de persulfato de amônio (25\%) durante 10 segundos e, logo após, lavadas com água e então secadas com ar comprimido, inspecionadas e fotografadas.

\subsubsection{Caracterização Microestrutural}

As amostras do aço em estudo, tanto laminadas a quente (BQ) quanto laminadas a frio (BF), foram preparadas de forma tradicional para caracterização microestrutural: corte; embutimento a quente (baquelite), lixamento (carbeto de silício: de 100 a 1200 mesh, sucessivamente, usando água); polimento manual (pasta de diamante de $3 \mu \mathrm{m}$ e $1 \mu \mathrm{m}$, no caso da $B Q$, e diamante policristalino de $3 \mu \mathrm{m}$ em suspensão e sílica coloidal de $0,05 \mu \mathrm{m}$, no caso da BF). Para análise morfológica da microestrutura, as amostras foram atacadas por imersão (Nital 2\% para BQ e Nital 3\% para BF), durante 30 segundos, ou até que as amostras ficassem foscas, ao passo que, para análise de profundidade de corrosão intergranular, não foram utilizados ataques químicos, visando não mascarar nem acentuar a profundidade da corrosão.

As amostras de BQ foram observadas em um Microscópio Eletrônico de Varredura (MEV), JEOL JSM7100F FEG (25kV, detector de elétrons secundários para 
morfologia e retroespalhados para análise de corrosão intergranular, $10 \mathrm{~mm}$ de distância de trabalho). As amostras de BF foram observadas no Microscópio Óptico (MO) Leica, modelo DMLM, para análise da corrosão intergranular, nível de coalescimento e também para avaliar o nível de inclusões.

\subsubsection{Caracterização Mecânica}

Dois corpos de prova $\left(L_{0}=50 \mathrm{~mm}\right)$ foram extraídos da $B Q$ na direção longitudinal por condição de tratamento e os ensaios realizados conforme ABNT NBR ISO 6892-1 em máquina ZWICK Z250, extensômetro de contato (strain-gauge). Foram realizados também ensaios de dureza Rockwell ( $B$ ou $C$ ) nas amostras tanto de $B Q$ quanto de BF. No caso das amostras de BQ, estes ensaios foram realizados em durômetro Emco, modelo M4U-025 e, no caso das amostras de BF, em durômetro Wolpert, modelo Diatestor 2RC, ambos realizados conforme ABNT NBR 6671.

\section{RESULTADOS E DISCUSSÃO}

A corrida experimental foi vazada em caráter experimental na ArcelorMittal Tubarão, apresentando placas ausentes de trincas (longitudinais, transversais, laterais ou de quina) e com leve segregação central (Figura 7), que é inerente do processo de lingotamento contínuo, principalmente para materiais com o nível de $\mathrm{C}$ e ligas do aço aqui estudado.

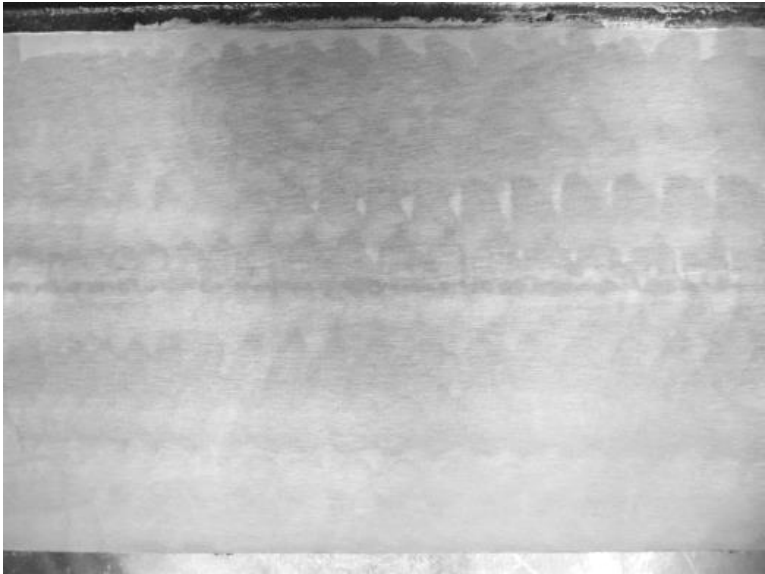

(a)

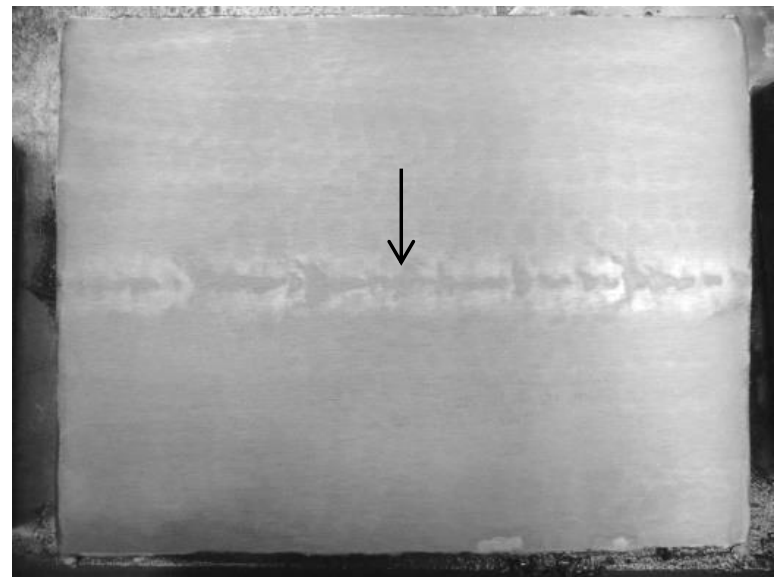

(b)

Figura 7. Resultados de Macro ataque do aço BW BL 8660 (a) transversal e (b) longitudinal ao sentido de lingotamento.

Após o lingotamento, as placas foram resfriadas lentamente em fossas e então enfornadas para laminação a quente, que se sucedeu sem anormalidades. A laminação deste aço é realizada sob um rigoroso controle de temperaturas de acabamento e bobinamento, velocidade de laminação e de vazão total de água no laminar flow. Estes controles objetivam tanto a formação de uma microestrutura controlada quanto à segurança, evitando que a tira venha a sofrer têmpera excessiva, que pode aumentar demasiadamente a fragilidade do material e causar possível ruptura. As análises metalográficas da BQ (Figura 8a e b) mostraram microestrutura homogênea formada por perlita fina em quase sua totalidade, com pequenas porções de ferrita e pequena ocorrência de corrosão intergranular na condição mais crítica, posição central das espiras internas (Figura 8c e d). 


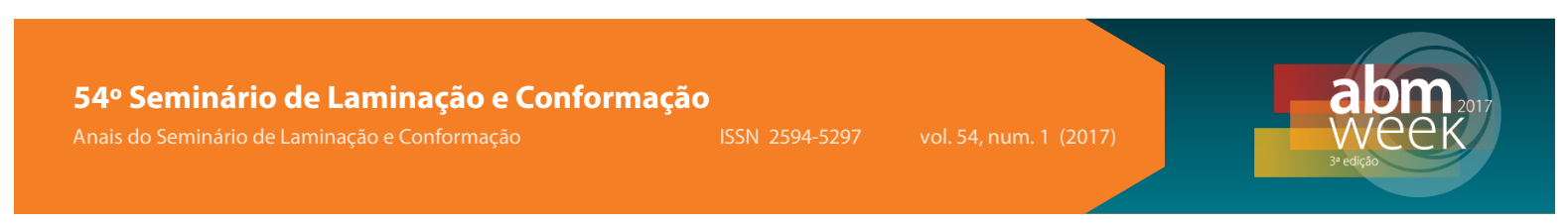

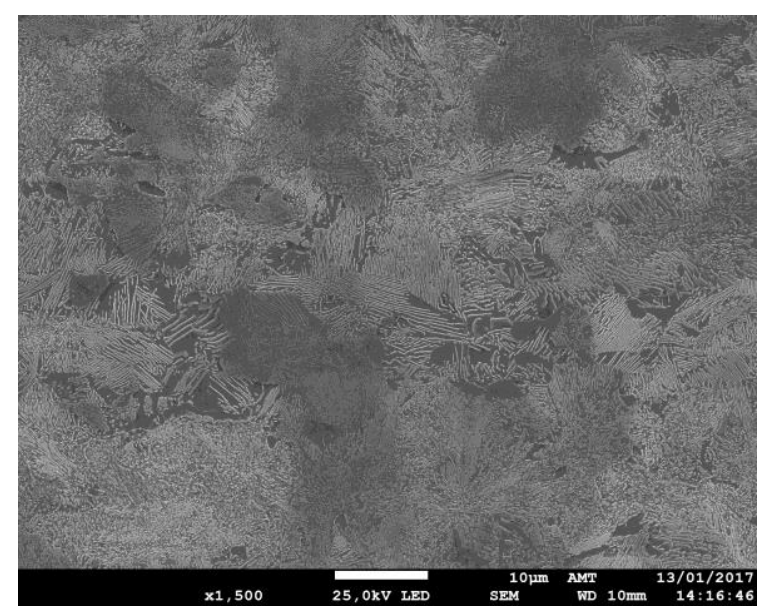

(a)

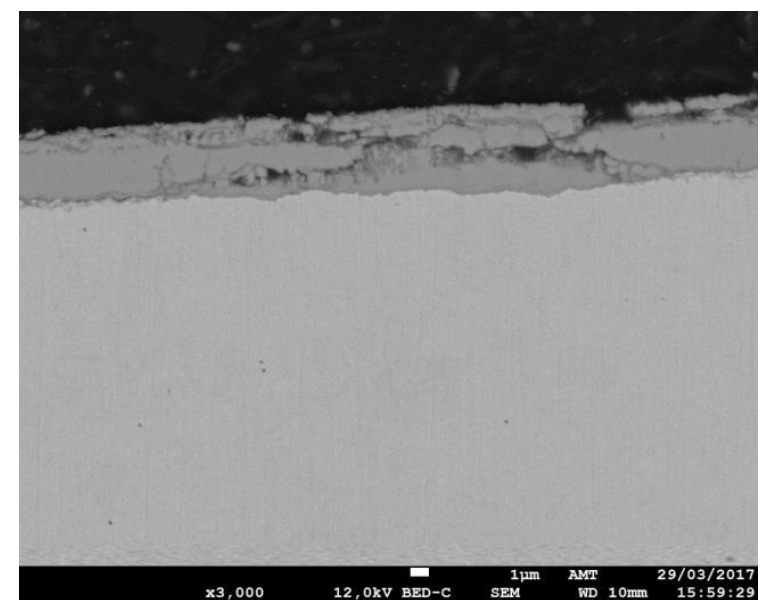

(c)

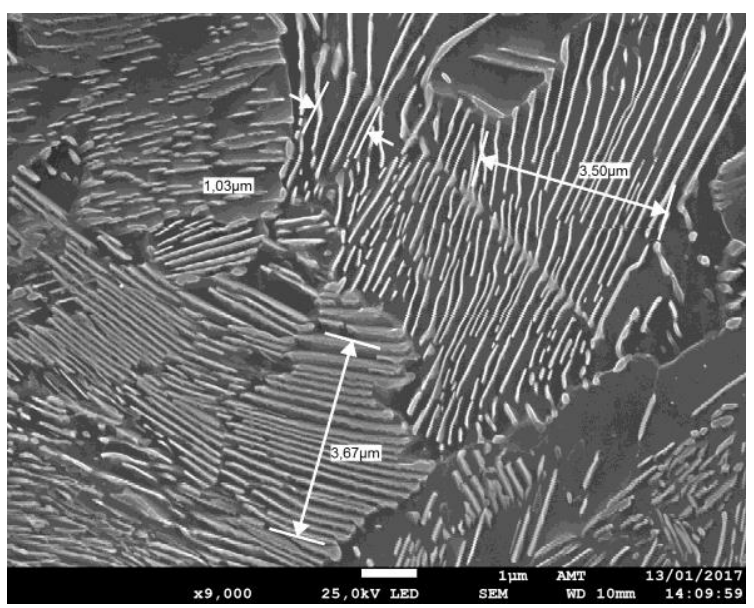

(b)

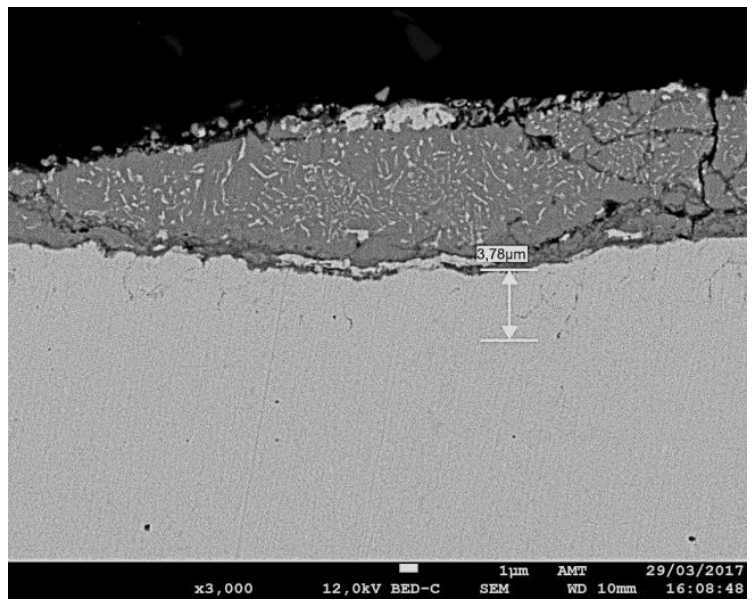

(d)

Figura 8. Micrografias da BQ do aço BW BL 8660 (a) com menor aumento e (b) com maior aumento, posição centro-meio, $\mathrm{MO}$, e micrografias da região próxima à superfície nas posições (c) centro-topo

e (d) centro-meio. MEV - (a e b) Imagens de elétrons secundários, Nital 2\% e (c e d) imagens de elétrons retroespalhados, sem ataque.

Os resultados dos ensaios mecânicos da $B Q$ apresentaram valores relativamente baixos de limite de escoamento (LE), altos valores de limites de resistência (LR) e alongamento (Tabela 2), condizentes com a composição química do aço estudado, refletindo diretamente a microestrutura refinada e homogênea obtida (Figura $8 a$ e b). Os resultados de dureza obtidos acompanham diretamente os valores de LE obtidos.

Tabela 2. Propriedades mecânicas do aço BW BL 8660 - Longitudinal, base $50 \mathrm{~mm}$

\begin{tabular}{ccccc} 
Posição & LE (MPa) & LR (MPa) & Al (\%) & Dureza (HRC) \\
\hline Topo & 586 & 840 & 21 & 27 \\
\hline Meio & 554 & 919 & 17 & 24 \\
\hline Cauda & 545 & 879 & 19 & 21
\end{tabular}

A BQ então foi enviada para a Waelzholz Brasmetal Laminação para continuação do processo de produção (decapagem, laminação a frio, recozimento, etc). Ao final dos processos supracitados, as análises metalográficas realizadas revelaram a presença de corrosão intergranular, 3,39 $\mu \mathrm{m}$ de profundidade (Figura 9a), elevado nível de limpidez, nível de inclusão C1F segundo ASTM E45 (Figura 9a) e microestrutura 
100\% esferoidizada (Figura 9b), conforme figura 3.0 da Série de Diagramas da Norma SEP 1520, e o ensaio de dureza apontou dureza de 86HRB (6HRC estimado). Em seu estado final como componente de corrente de motosserra, Figura 9c, a avaliação microestrutural após austêmpera, Figura 9d, revelou microestrutura completamente bainítica e o ensaio de dureza mostrou dureza 52HRC. Estas características microestruturais, juntamente com os resultados de dureza obtidos ao longo do processamento (BQ, BF e aplicação final) evidenciam que o material objeto deste estudo apresenta características adequadas à laminação a frio e conformação como fornecido (BQ e BF, respectivamente) e, devido aos elevados teores de ligas (C, $\mathrm{Cr}$, Ni e Mo), excelente temperabilidade, sendo adequado para posteriores processos tanto de têmpera (visando microestrutura martensítica) quanto austêmpera (visando microestrutura bainítica - Figura 9d).

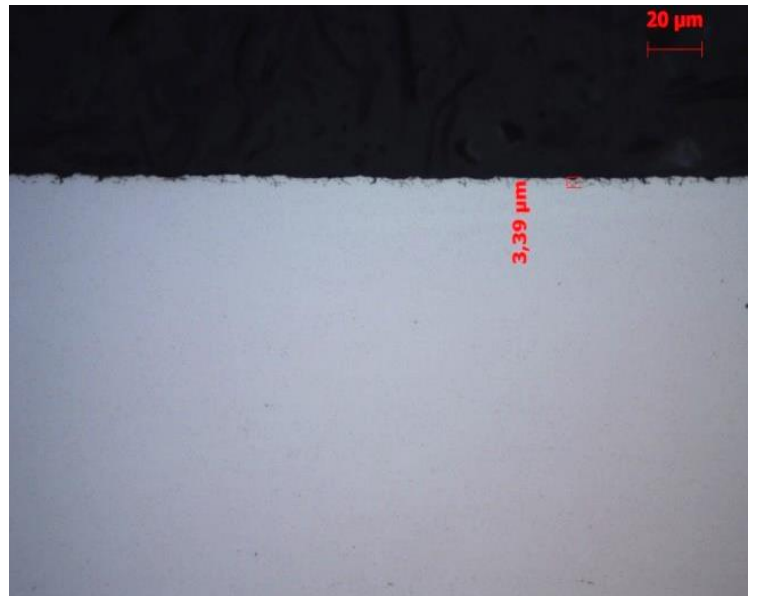

(a)

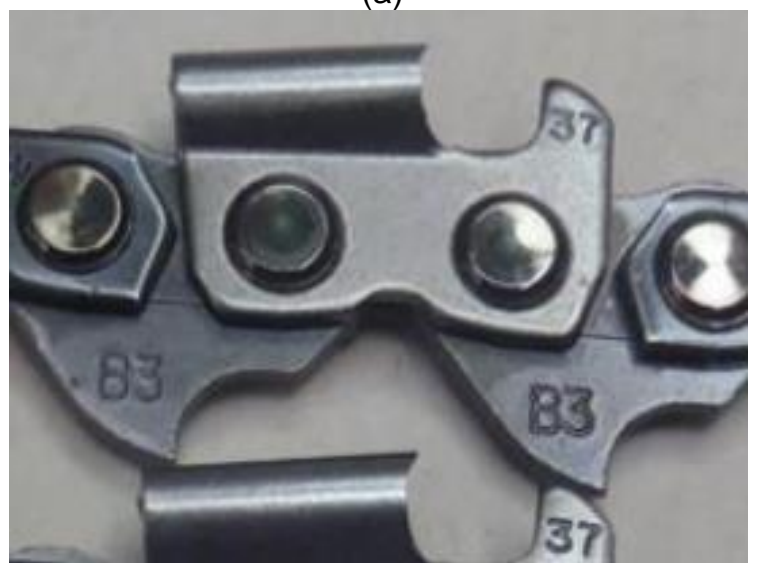

(c)

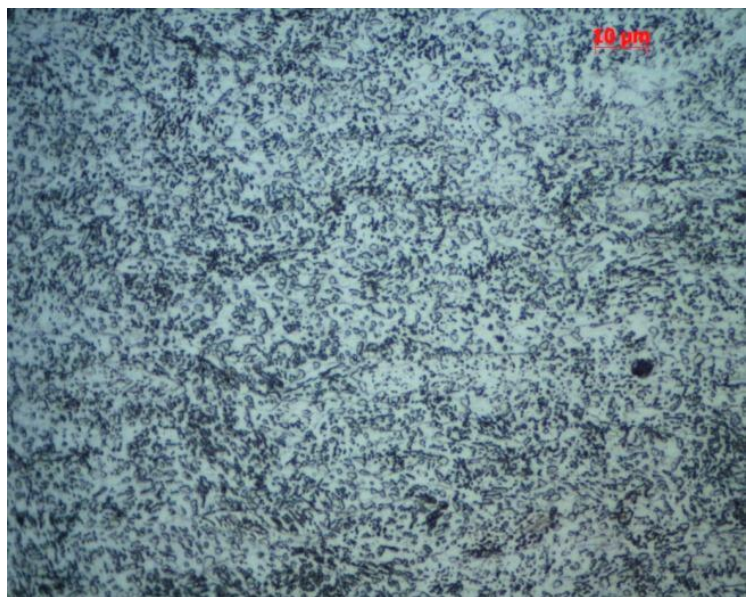

(b)

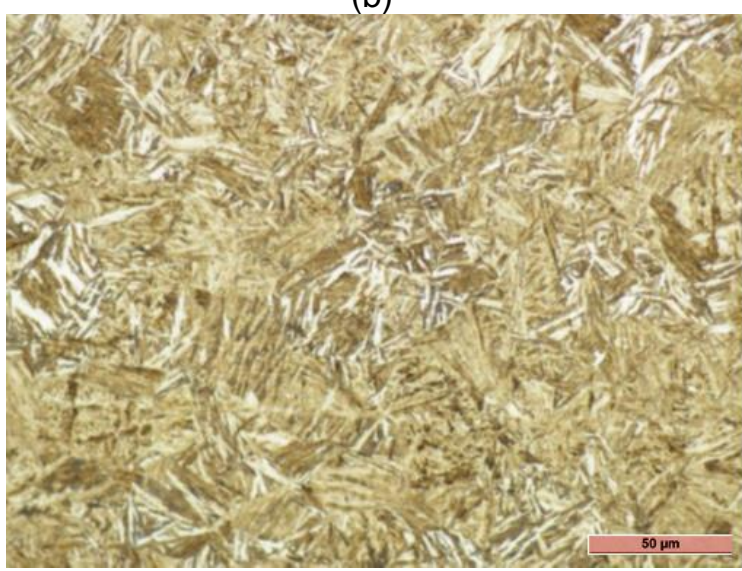

(d)

Figura 9. Micrografias da BF do aço BW BL 8660 (a) sem ataque e (b) com ataque Nital 3\%. (c) Componente de motosserra montado e (d) micrografia do aço austemperado com ataque Nital $3 \%$.

Pode-se observar, ao longo deste trabalho, a importância do controle microestrutural do aço com o intuito de melhorar o desempenho no processo subsequente como, por exemplo, a obtenção de uma microestrutura perlítica fina e homogênea, ideal para laminação a frio, conforme mostrado nas Figuras 2c, 8a e 8b, microestrutura completamente esferoidizada, de maior conformabilidade, conforme mostrado nas Figuras 2a e 9b, e microestrutura bainítica, ideal para desempenho tanto em fadiga quanto para resistência ao desgaste. 


\section{CONCLUSÃO}

- Este trabalho possibilitou a revisão bibliográfica das possíveis microestruturas que podem ser obtidas com o aço alto carbono baixa liga avaliado, assim como a correlação das mesmas com o processamento e aplicação do aço;

- Os resultados aqui descritos evidenciam a importância do controle minucioso de todo o processo siderúrgico, desde a Aciaria até o Recozimento, para a obtenção de um aço de elevada limpidez e desempenho, utilizando o conhecimento metalúrgico para adequação microestrutural do aço para cada etapa do processo produtivo;

- Os resultados encontrados neste experimento mostram total aptidão do aço BW BL 8660 à aplicação, devido ao atendimento pleno às características metalúrgicas consideradas críticas à aplicação;

- Observa-se também a importância do controle microestrutural ao longo do processo, visando aperfeiçoar o desempenho do aço tanto do processo subsequente quanto no uso final.

\section{REFERÊNCIAS}

1 Oliveira, F. C. Analise da influência dos ciclos térmicos de diferentes projetos de fornos de recozimento contínuo na microestrutura e propriedades mecânicas de aços bifásicos. Dissertação de Mestrado - Programa de Pós-graduação em Engenharia de Materiais - Universidade Federal de Minas Gerais, Belo Horizonte, 2013.

2 Lopes, A. S. et al. Desenvolvimento do Aço SAE 1070 na ArcelorMittal Tubarão e análise da conformabilidade através da relaminação na Brasmetal Waelzholz. $50^{\circ}$ Seminário de Laminação da ABM, Ouro Preto-MG, Brasil, Anais, 2013.

3 Bhadeshia, H. K. D. H. Alternatives to the Ferrite-Perlite Microstructure. Materials Science Forum, Vols. 284-286, p. 39-50, 1998.

4 Honeycombe, R. W. K.; Bhadeshia, H. K. D. H. The bainitic reaction, Metallurgical and Materials Science Steels: Microestruture and Properties, p. 115-139, 1995.

5 Bhadeshia, H. K. D. H. Bainite in Steels: Transformations, Microstructure and Properties. Segunda edição. IOM Communications Ltd, London, Reino Unido, 2001.

6 Rios, P. R., Padilha, A. F. Transformações de fase, Artliber, São Paulo, 2007.

7 Honeycombe, R. W. K. Aços: Microestrutura e Propriedades, Fundação Calouste Gulbenkian, Lisboa, Portugal, 1982.

8 Totten, G. E., Howes, M. A. H. Steel Heat Treatment Handbook, Marcel Dekker Inc., EUA, 1997.

9 Ronqueti, L. A. et al. Study of grain boundary oxidation of high alloyed carbon steels at coiling temperature. 53ํㅗㄹ Seminário de Laminação da ABM, Rio de Janeiro-RJ, Brasil, Anais, 2016.

10 Auinger, M. et al. Grain boundary oxidation in iron-based alloys, investigated by 180 enriched water vapour - The effect of mixed oxides in binary and ternary $\mathrm{Fe}-\{\mathrm{Al}, \mathrm{Cr}, \mathrm{Mn}$, Si\} systems. Corrosion Science. 96:133-143, 2015. 